\title{
A Novel Tris(2-aminoethyl)amine Based Tripodal Ligand: Synthesis and Solution Coordination Studies with Trivalent Iron and Chromium
}

\author{
Minati Baral, ${ }^{1}$ Amit Gupta, ${ }^{1}$ Rifat Akbar, ${ }^{2}$ and Bikram K. Kanungo ${ }^{2}$ \\ ${ }^{1}$ Department of Chemistry, National Institute of Technology, Kurukshetra, Haryana 136119, India \\ ${ }^{2}$ Department of Chemistry, Sant Longowal Institute of Engineering and Technology, Longowal, Punjab 148106, India
}

Correspondence should be addressed to Minati Baral; minatibnitkkr@gmail.com

Received 31 July 2016; Accepted 19 October 2016

Academic Editor: Khalid Z. Elwakeel

Copyright (C) 2016 Minati Baral et al. This is an open access article distributed under the Creative Commons Attribution License, which permits unrestricted use, distribution, and reproduction in any medium, provided the original work is properly cited.

\begin{abstract}
A novel tris (2-aminoethyl)amine (TREN) based tripodal ligand TRENOL (L) has been synthesized and characterized by elemental analysis and UV-VIS, IR, ${ }^{1} \mathrm{H}$, and ${ }^{13} \mathrm{C}$ NMR spectroscopic methods. The coordination behaviour of the ligand with $\mathrm{H}^{+}$and trivalent metal ions, $\mathrm{Fe}(\mathrm{III})$ and $\mathrm{Cr}(\mathrm{III})$, was investigated in aqueous medium at $0.1 \mathrm{M} \mathrm{KCl}$ at $25 \pm 1^{\circ} \mathrm{C}$ by potentiometric and spectrophotometric studies. Tripodal ligand showed seven protonation constants in the adopted $\mathrm{pH}$ range 2-11 and its electronic spectra exhibited three bands at 216,323, and $423 \mathrm{~nm}$. Ligand formed various metal complex species of the type $\mathrm{MLH}_{5}, \mathrm{MLH}_{4}$, $\mathrm{MLH}_{3}, \mathrm{MLH}$, and ML with trivalent metal ions. The determined values of the formation constants (for ML species) of the ligand with $\mathrm{Fe}(\mathrm{III})$ and $\mathrm{Cr}(\mathrm{III})$ were 24.19 and 18.64, respectively. Molecular modeling studies revealed that the metal complexes formed distorted octahedral geometry. Besides, ligand showed fluorescence at $496 \mathrm{~nm}$ when excited at $289 \mathrm{~nm}$. The fluorescence behaviour of the ligand in the presence of $\mathrm{Fe}$ (III) ions showed noticeable quenching in comparison to the other metal ions at physiological $\mathrm{pH}$ (7.4). So, as per the outcomes of the present study, TRENOL has the potential to be used as the iron detector in environmental, agricultural, and medical fields.
\end{abstract}

\section{Introduction}

Multifunctional compounds such as polyphenols are highly abundant in natural products like pine, grape, and witch hazel products. They are broadly beneficial for human health as they are found highly active and protective for red blood cells from free radical induced hemolysis. However, polyphenols serve as double-edged sword due to their both antioxidative and prooxidative properties. They are capable of scavenging free radicals and in other cases can serve as reactive oxygen species [1] and, hence, can be explored either as an effective antioxidant or as a cytotoxic agent in various hyperproliferative diseases. Besides biological studies, polyphenols based Schiff bases can be designed to demonstrate the coordination behaviour of these biological potent agents with metal ions which may further provide additive properties to this class of compounds. Schiff bases are much prevailing compounds in coordination chemistry due to their capability of forming stable complexes with metal ions [2]. They are known for their high selectivity and sensitivity with specific metal ions and so they are useful in potentiometric sensing and heterogeneous catalytic processes [3]. Despite their high significance against potent pathogens only limited data is available in the field of metal complexation. This less investigated area can be studied for better understanding of electronic, molecular, and spectral behaviour of polyphenols based Schiff bases and their metal complexes. Such studies provide a strong ground for the development of novel sensor or agents with wider applications.

Iron overload transfusion therapy is generally used to cure such a metal poisoning, which includes administration of iron chelating agents [4]. Potential chelators are biologically available and are featured by lesser toxicity, high selectivity towards iron, and forming stable complex upon binding with it. In these aspects, low molecular weight naturally occurring biomolecules, siderophores, have 
capability to bind with iron with high affinity and specificity. Nowadays, iron uptake by those biomolecules is serving as a novel platform for various applications, based on iron uptake mechanism such as drug delivery system [5, $6]$, detection of microorganisms $[7,8]$, and capture and accumulation of actinide elements [9-11]. In order to put some appropriate solution, synthesis of novel molecules is required which may be considered against intoxication of aforesaid metals in the biological systems and may also be used for developing some sought probes for the detection of these metals in trace quantity if present in the surrounding environment.

Moreover, for developing novel chelators, it is necessary to cover the structural aspects of natural occurring molecules such as siderophores. During the worldwide search for potential siderophore mimic chelators, it has been observed that several research groups have developed different strategies for synthesis of such tripodal chelating agents. Much effort has been channeled into the synthesis of catechols [12] and hydroxamates [13-16] with typical examples (model chelators) being enterobactin and desferrioxamine, respectively. The most important work was carried out by the Raymond group who have reported numerous catecholate [17] and hydroxypyridone ligands [18, 19]. A number of synthetic analogues have been prepared which retain the high affinity for iron(III) and with other metal ions, typical of enterobactin, and yet are more stable under biological conditions, for instance, the tripodal molecular Mecam [20]. Mecam is the structural analogue of enterobactin and has three catechol binding units: the catecholamide groups are appended to 1,3,5-triaminomethyl benzene rather than to the tri-L-serine ligand backbone of enterobactin. Many derivatives of Mecam have been reported [12, 21-23]. The thermodynamics, kinetics, and electrochemical studies along with biological evaluation of these ligands are reported in numerous articles and reviews [24, 25]. Attempts have been made to synthesize lipophilic tripodal hexadentate ligand, where three bidentate moieties are attached to core by stable arms such as carbon chain and ether linkers [26, 27] containing C-pivot, tris(aminomethyl)ethane (tame) as center unit. Another important aspect is the ring strain due to the rigidity of the benzene ring, as it could be expected if the $\mathrm{sp}^{2}$ hybridized atoms of benzene ring are replaced with $\mathrm{sp}^{3}$ hybridized systems like cyclohexane ring, the resulting tripod system would be more flexible and ring strain will be less compared to Mecam and complexes would be thermodynamically more stable [28]; design of such tripodal systems by replacing benzene ring with a cyclohexane ring has been reported [29-33].

Though many tripodal siderophore mimics containing phenolate, catecholate, and other binding units have been reported, very few pyrogallol type multidentate chelators have been reported [34] and detailed studies have been reported. Keeping in view of the above, a polyhydroxy tripodal ligand incorporated with azomethine spacer has been synthesized from TREN and 2,3,4-trihydroxybenzaldehyde and its coordination behaviour towards $\mathrm{Fe}(\mathrm{III})$ and $\mathrm{Cr}$ (III) is studied.

\section{Experimental}

2.1. Chemicals and Solvents. Reagents for synthesis purpose of tris(2-aminoethyl)amine (TREN), 2,3,4-trihydroxybenzaldehyde, and so forth were purchased from SigmaAldrich and used without further purification. Analytical grade solvents tetrahydrofuran, ethanol, and others were purchased from Loba Chemie Pvt. Ltd. and Fisher Scientific. Before using, solvents were dried over suitable drying reagents. Solvents were freshly distilled over appropriate drying agents following standard procedures.

2.2. Physical Measurements. Melting points of the compounds were determined on Microsil apparatus. Elemental analysis (CHN) was performed on Euro EA 3000, $60 \mathrm{~Hz}-$ $1200 \mathrm{~W}$ elemental analyzer. For FT-IR analyses, the sample was carefully mixed in homogenous manner in $\mathrm{KBr}$ in 1:100 by weight and a fine pellet was prepared under pressure. The FT-IR spectrum of the compound was taken under transmission mode with Perkin-Elmer FT-IR spectrometer in mid-range region (4000-400) $\mathrm{cm}^{-1}$. The ${ }^{1} \mathrm{H}$ and ${ }^{13} \mathrm{C}$ NMR spectra of the ligand TRENOL were taken in $\mathrm{d}_{6}$ dmso using Bruker Avance II 400 NMR spectrometer. The chemical shifts were quantified in $\delta$ values (ppm). Tetramethylsilane was used as an internal reference. To avoid solubility problem, the compound was converted into its hydrochloric salt and dissolved in millipore grade deionized water. Ionic strength of the solution was adjusted with $0.1 \mathrm{M} \mathrm{KCl}$. All the stock solutions were prepared in millipore grade deionized water. For weighing appropriate amount, high precision weighing balance CAS-CAUW220D was used (up to level of four digits). The exact concentration of $\mathrm{KOH}(0.1 \mathrm{M})$ was determined potentiometrically using $0.1 \mathrm{M}$ solution of oxalic acid as primary standards and then exact strength of $\mathrm{HCl}(0.1 \mathrm{~N})$ was determined by the same method using standardized $\mathrm{KOH}$. All the solutions were prepared with millipore grade deionized water immediately before use, which was deoxygenated and flushed continuously with grade $\mathrm{I}_{2}$ gas to exclude $\mathrm{CO}_{2}$ and $\mathrm{O}_{2}$. All measurements were carried out at $25 \pm 1^{\circ} \mathrm{C}$ maintained by using thermostat.

2.3. Synthesis and Characterization. $0.146 \mathrm{~g}(1.0 \mathrm{mmol})$ of TREN was added gradually to the stirring solution of $0.4673 \mathrm{~g}$ (3.0 mmol) 2,3,4-trihydroxy-benzaldehyde dissolved in absolute ethanol $(30.0 \mathrm{~mL})$ under nitrogen gas atmosphere for $12 \mathrm{~h}$ at room temperature (Figure 1). The obtained yellowishorange precipitates were filtered and subjected to crystallization in methanol/tetrahydrofuran solvent mixture. The yellow colour solid (TRENOL) with yield $80 \%$ and melting point $186-188^{\circ} \mathrm{C}$ was characterized by elementary analysis and different spectroscopic techniques. Elemental analysis of carbon $(\mathrm{C})$, hydrogen $(\mathrm{H})$, and nitrogen $(\mathrm{N})$ in percentage was found to be $\mathrm{C} 57.83, \mathrm{H} 5.62, \mathrm{~N}$ 10.12; calculated $\left(\mathrm{C}_{27} \mathrm{H}_{30} \mathrm{~N}_{4} \mathrm{O}_{9}\right), \mathrm{C} 58.54, \mathrm{H} 5.52, \mathrm{~N}$ 10.14. IR (KBr) $v_{\max } / \mathrm{cm}^{-1}$ : $3365(\mathrm{O}-\mathrm{H}), 2925$ (N-H amide), 1595 (-C=N-), 1352 (oop, C$\left.\mathrm{O}-\mathrm{H} \mathrm{cm}^{-1}\right) ;{ }^{1} \mathrm{H}$ NMR spectra $\delta(400 \mathrm{MHz}, \mathrm{dmso}), \delta$ (ppm): $2.7\left(\mathrm{t}, 6 \mathrm{H}, J=8.1,-\mathrm{CH}_{2}-\right), 2.9\left(\mathrm{t}, 6 \mathrm{H}, J=8.1-\mathrm{CH}_{2}-\right), 6.0-$ $7.0(\mathrm{~m}, 6 \mathrm{H}, J=8.0, \mathrm{Ar}-\mathrm{H}), 9.7(\mathrm{~s}, 3 \mathrm{H},-\mathrm{N}=\mathrm{CH}-), 7.0(\mathrm{~s}, 3 \mathrm{H}$, -OH), 7.9 (s, 3H, - OH), $8.2(\mathrm{~s}, 3 \mathrm{H},-\mathrm{OH}) ;{ }^{13} \mathrm{C}$ NMR spectra $\delta$ 


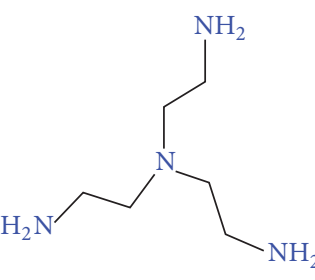

(a)

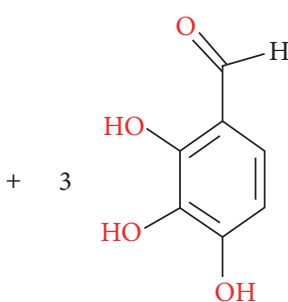

(b)

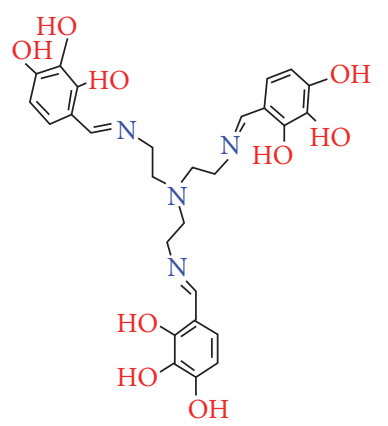

(c)

FIGURE 1: Scheme for synthesis of tripodal Schiff base. (a) TREN; (b) 2,3,4-trihydroxy-benzaldehyde; (c) TRENOL.

(400 MHz, dmso): $\delta=106-158$ (18C, - Ar), $164(3 \mathrm{C},-\mathrm{N}=\mathrm{CH}-)$, $55\left(3 \mathrm{C},-\mathrm{CH}_{2}\right), 53\left(3 \mathrm{C},-\mathrm{CH}_{2}\right)$.

2.4. Potentiometric Titration. Determination of protonation constants $(\log K)$ of the ligand and its formation constants $(\log \beta)$ with two trivalent metal ions, $\mathrm{Fe}(\mathrm{III})$ and $\mathrm{Cr}(\mathrm{III})$, was done by potentiometry and spectrophotometry methods. The potentiometric titrations were carried out on $\mathrm{HACH}$ Sension2 potentiometer using glass electrode and $\mathrm{pH}$ was recorded as $-\log \left[\mathrm{H}^{+}\right]$. The standard method was used for electrode calibration in suitable buffers of $\mathrm{pH} 4$ and $\mathrm{pH} 7$ [35]. All the titrations were carried out using auto pipette with least count $10 \mu \mathrm{M}$ and capacity $1.0 \mathrm{~mL}$. In potentiometric method final concentration $1 \times 10^{-5} \mathrm{M}$ was fixed for both ligands and metal ions. The ligand solution, in the absence and presence of metal ions, was titrated against $0.1 \mathrm{M} \mathrm{KOH}$ at $\mu=0.1 \mathrm{M}$ $\mathrm{KCl}$ at $25 \pm 1^{\circ} \mathrm{C}$ in $\mathrm{pH}$ range $2-11$ and adequate time was given for the attainment of the equilibrium to give a stable $\mathrm{pH}$ reading. Hyperquad 2006 nonlinear least square program was used for the refinement of potentiometric data [36]. During the titration with increasing $\mathrm{pH}$, the species formed were observed using the simulation program HYSS 2009 [37].

2.5. Spectrophotometric and Fluorescence Studies. Spectrophotometric titrations were carried out under the same conditions by keeping the final ligand concentration $2 \times 10^{-5} \mathrm{M}$. During titration after each addition of base $\mathrm{KOH}$, sufficient time was allowed for establishment of the equilibrium and a small aliquot of the solution was taken in to the cuvette $(1 \mathrm{~cm}$, path length) to take the spectra. The computer software HypSpec [38] was used for the determination of protonation constants of the ligand and formation constants of the metal complexes with $\mathrm{Fe}(\mathrm{III})$ and $\mathrm{Cr}(\mathrm{III})$.

The fluorescence study of the ligand was conducted on Agilent Fluorescence Spectrophotometer. The emission spectra of the ligand in the absence and presence of metal ions in 1:1 M-L stoichiometry were studied with $\lambda_{\text {ex }}=289 \mathrm{~nm}$ in the same method under similar conditions as mentioned for spectrophotometric titrations in $\mathrm{pH}$ range 2-9. Also, the effect of increasing concentration of the Fe(III) (2 to $1000 \mu \mathrm{M})$ on the fluorescence intensity of the tripodal ligand $(20 \mu \mathrm{M})$ was investigated at $\mathrm{pH} 7.4 \pm 0.1$ using HEPES buffer. In a similar way fluorescence behaviour of the ligand was also studied in the presence of metal ion $\left(\mathrm{Na}^{+}, \mathrm{K}^{+}, \mathrm{Ca}^{2+}\right.$, $\mathrm{Mg}^{2+}, \mathrm{Zn}^{2+}, \mathrm{Co}^{2+}, \mathrm{Pb}^{2+}, \mathrm{Cu}^{2+}, \mathrm{Al}^{3+}$, and $\left.\mathrm{Cr}^{3+}\right)$. Moreover, the detection limit was calculated for the iron on the basis of fluorescence titration at $\mathrm{pH} 7.4$ according to the definition by IUPAC, that is, $3.3 * \mathrm{SD} / m$, where "SD" is the standard deviation of the fluorescence intensity of the blank (ligand only) and " $m$ " is the slope of the calibration curve constructed between fluorescence intensity of ligand $(20 \mu \mathrm{M})$ at $490 \mathrm{~nm}$ and the concentration of $\mathrm{Fe}(\mathrm{III})$ in $\mu \mathrm{M}$. For determining the SD, the fluorescence emission spectra of the blank were measured 10 times [39].

2.6. Molecular Modeling and Computational Methods. All computational simulations were done on a Pentium DualCore $3.20 \mathrm{GHz}$ machine in Windows XP environment. The initial structures of the ligand and their metal complexes for optimization were manually drawn using Symyx Draw. The initial geometry optimization of the ligands, its protonated and deprotonated species obtained in solution, and its metal complexes leading to minimum strain energy was achieved through molecular mechanics calculation using MM+ force field by software HyperChem version 7.5 [40]. The obtained structure of the ligand was reoptimized semiempirically using PM3, self-consistent fields (SCF) method [41]. The steepest descent method followed by Polak-Ribiere method with convergence limit of $0.0001 \mathrm{Kcal} / \mathrm{mol}$ and RMS gradient of $0.001 \mathrm{Kcal} / \mathrm{mol}$ was used to get geometry optimizations.

\section{Results and Discussion}

3.1. Synthesis and Characterization of TRENOL. A yellowishorange colour product (TRENOL) with reasonable yield $(80 \%)$ obtained from single condensation of TREN and 2,3,4-trihydroxybenzaldehyde is stable to air and has melting point $186-188^{\circ} \mathrm{C}$. The compound was completely soluble in dmso and partially soluble in ethanol but highly insoluble in dichloromethane, ether, acetonitrile, and so forth. Structural characterization of the tripodal ligand was done through FTIR, ${ }^{1} \mathrm{H},{ }^{13} \mathrm{C}$ NMR, and CHN analysis. The FT-IR spectrum of the ligand showing a sharp peak at $1595 \mathrm{~cm}^{-1}$ is due to $\nu(-\mathrm{C}=\mathrm{N}-)$ that ensured amine-aldehyde condensation and formation of the Schiff base. The strong band near $3365 \mathrm{~cm}^{-1}$ was obtained due to stretching vibration of the $-\mathrm{OH}$ group, 
TABLE 1: Stepwise protonation constants $(\log K)$ of the TRENOL (L), at $25 \pm 1^{\circ} \mathrm{C}$ and $\mu=0.1 \mathrm{M} \mathrm{KCl}$.

\begin{tabular}{lcc}
\hline Reaction & $\log K$ & Protonation sites \\
\hline $\mathrm{L}+\mathrm{H} \rightleftharpoons \mathrm{LH}$ & $10.02 \pm 0.04$ & $-\mathrm{O}^{-}$(aromatic) \\
$\mathrm{LH}+\mathrm{H} \rightleftharpoons \mathrm{LH}_{2}$ & $8.21 \pm 0.05$ & $-\mathrm{O}^{-}$(aromatic) \\
$\mathrm{LH}_{2}+\mathrm{H} \rightleftharpoons \mathrm{LH}_{3}$ & $7.83 \pm 0.03$ & $-\mathrm{O}^{-}$(aromatic) \\
$\mathrm{LH}_{3}+\mathrm{H} \rightleftharpoons \mathrm{LH}_{4}$ & $7.45 \pm 0.06$ & $-\mathrm{N}$ (apical) \\
$\mathrm{LH}_{4}+\mathrm{H} \rightleftharpoons \mathrm{LH}_{5}$ & $2.51 \pm 0.03$ & $-\mathrm{N}$ (imine) \\
$\mathrm{LH}_{5}+\mathrm{H} \rightleftharpoons \mathrm{LH}_{6}$ & $1.82 \pm 0.04$ & $-\mathrm{N}$ (imine) \\
$\mathrm{LH}_{6}+\mathrm{H} \rightleftharpoons \mathrm{LH}_{7}$ & $1.24 \pm 0.05$ & $-\mathrm{N}$ (imine) \\
$\mathrm{L} \rightleftharpoons \mathrm{LH}-1+\mathrm{H}^{+}$ & $-8.36 \pm 0.05$ & - \\
$\mathrm{L} \rightleftharpoons \mathrm{LH}_{-2}+2 \mathrm{H}^{+}$ & $-8.77 \pm 0.03$ & - \\
$\mathrm{L} \rightleftharpoons \mathrm{LH}_{-3}+3 \mathrm{H}^{+}$ & $-9.39 \pm 0.06$ & - \\
$\mathrm{L} \rightleftharpoons \mathrm{LH}_{-4}+4 \mathrm{H}^{+}$ & $-10.80 \pm 0.04$ & - \\
$\mathrm{L} \rightleftharpoons \mathrm{LH}_{-5}+5 \mathrm{H}^{+}$ & $-11.00 \pm 0.03$ & - \\
$\mathrm{L} \rightleftharpoons \mathrm{LH}_{-6}+6 \mathrm{H}^{+}$ & $-11.16 \pm 0.03$ & - \\
\hline
\end{tabular}

that is, $v(-\mathrm{OH})$. Another peak obtained at $2925 \mathrm{~cm}^{-1}$ was assigned to the $\nu(-\mathrm{NH})$ of the amide linkage. Theoretical IR values were calculated by using semiempirical/PM6 parameters which showed pattern of the peaks similar to that of the experimental IR. The ${ }^{1} \mathrm{H}$ NMR spectra of the ligand showed peaks at $2.7 \mathrm{ppm}$ and $2.9 \mathrm{ppm}$ which correspond to the methylene group $\left(-\mathrm{CH}_{2}\right)$ present in the vicinity of bridgehead nitrogen and imine groups, respectively. The signal that appeared at $9.7 \mathrm{ppm}$ was assigned to the $-\mathrm{HC}=$ group and presence of aromatic ring was confirmed from a multiplet found in the range $6.0-7.0 \mathrm{ppm}$. Singlets obtained between 7.0 and $8.2 \mathrm{ppm}$ correspond to the -OH groups of the aromatic ring [42]. In ${ }^{13} \mathrm{C}$ NMR spectra, the peak obtained at $164 \mathrm{ppm}$ confirmed the presence of imine group in the ligand and signals near 53 and $55 \mathrm{ppm}$ ensured the presence of methylene groups. The aromatic ring $\mathrm{C}$-atoms appeared in the range $106-158 \mathrm{ppm}$.

3.2. Determination of Protonation Constants. The protonation constants of the ligand were determined by potentiometric and spectrophotometric studies. Due to solubility limitation of the ligand in aqueous medium its hydrochloric salt was prepared prior to investigation. The neutral form of the ligand is considered as $\mathrm{LH}_{3}$ and the fully protonated form is considered as $\left(\mathrm{LH}_{7}\right)^{4+}$. The obtained values in the $\mathrm{pH}$ range 2-11 are defined by the following equations:

$$
\begin{aligned}
{\left[\mathrm{LH}_{n-1}\right]+[\mathrm{H}] } & \rightleftharpoons \mathrm{LH}_{n}, \\
K_{1 n} & =\frac{\left[\mathrm{LH}_{n}\right]}{\left[\mathrm{LH}_{n-1}\right][\mathrm{H}]} .
\end{aligned}
$$

Analysis of the curve (Figure 2) using Hyperquad offered seven protonation constants $(\log K)$ as shown in Table 1.

Although ligand TRENOL has thirteen dissociable protons, only seven protons could be deprotonated in the adopted experimental $\mathrm{pH}$ range $2-11$. The first three protonation constants were attributed to the ortho -OH groups of the aromatic ring. However, deprotonation of meta and

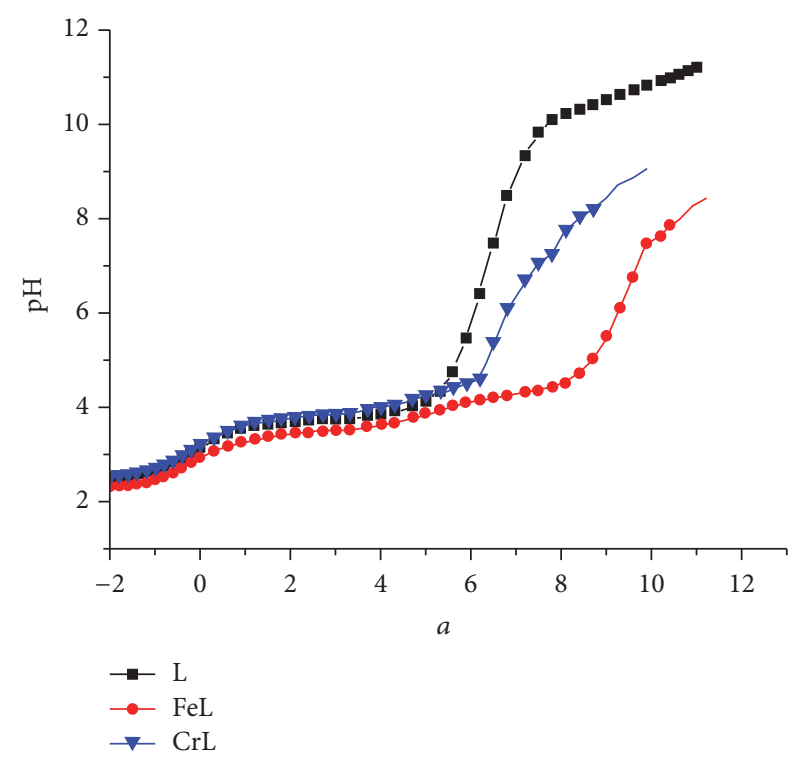

Figure 2: Potentiometric titration curves between $\mathrm{pH}$ and " $a$ " (moles of base added per mole of the ligand) in the presence of metal ions, $\mathrm{Fe}(\mathrm{III})$, and $\mathrm{Cr}(\mathrm{III})$ in $1: 1$ molar ratio; $[\mathrm{M}]=[\mathrm{L}]=1 \times 10^{-5} \mathrm{M}$ at $\mu=0.1 \mathrm{M} \mathrm{KCl}$ and $T=25 \pm 1^{\circ} \mathrm{C}$.

para $-\mathrm{OH}$ groups could not be obtained due to the presence of intramolecular $\mathrm{H}$-bonding and enhanced electron density in the ring which triggers after deprotonation of ortho hydroxy groups. The fourth protonation constant pertained to the apical nitrogen and the remaining three belong to azomethine groups. The obtained protonation constants for -OH groups (aromatic ring), apical " $\mathrm{N}$," and $-\mathrm{C}=\mathrm{N}$ - groups were in good agreement with the existing literature [42, 43]. The experimental curve did not give complete match with the theoretical curve at higher $\mathrm{pH}$ (i.e., >8.5) by only considering seven protonation constants, but by inclusion of six hydrolyzed species, namely, $\mathrm{LH}_{-1}, \mathrm{LH}_{-2}, \mathrm{LH}_{-3}, \mathrm{LH}_{-4}$, $\mathrm{LH}_{-5}$, and $\mathrm{LH}_{-6}$ in the model, the refinement process gave best fit to the experimental curve.

Also, as evident from the literature, Schiff bases are less stable in an alkaline medium and undergo hydrolysis [44]. The existence of various deprotonated and hydrolyzed species was $\mathrm{pH}$ dependent and formation of such species at different $\mathrm{pH}$ is evident from the species distribution diagram (Figure 3).

Protonation constants of the ligand were also obtained from the spectrophotometric technique. Analysis of spectrophotometric data obtained in $\mathrm{pH}$ range 2-9 also confirmed the seven protonation constants of the ligand and all were found in good agreement with the potentiometric data (Figure 4). Appearance of new absorption band and enhancement in the intensity implicate the deprotonation of the chromophoric groups. The electronic spectra of the ligand showed three bands at 216, 289, and $423 \mathrm{~nm}$ at low $\mathrm{pH} \sim 2$ and were assigned to $\pi \rightarrow \pi^{*}$ (former two) and $n \rightarrow \pi^{*}$ (latter one) transitions.

No significant change was found in the spectra of the ligand in the $\mathrm{pH}$ range $2-6$, but $\mathrm{pH}$ beyond this causes 
TABLE 2: Formation constants $(\log \beta)$ of $\mathrm{M}-\mathrm{L}$ complexes, where $\mathrm{M}=\mathrm{Fe}(\mathrm{III})$ and $\mathrm{Cr}(\mathrm{III}), \mathrm{A}=$ potentiometry, and $\mathrm{B}=$ spectrophotometry.

\begin{tabular}{|c|c|c|c|c|}
\hline & \multicolumn{2}{|c|}{$\mathrm{Fe}(\mathrm{III})$} & \multicolumn{2}{|c|}{$\mathrm{Cr}(\mathrm{III})$} \\
\hline & A & B & A & B \\
\hline$\frac{[\mathrm{ML}]}{[\mathrm{M}][\mathrm{L}]}$ & $24.01 \pm 0.03$ & $24.21 \pm 0.04$ & $18.64 \pm 0.07$ & $18.75 \pm 0.06$ \\
\hline$\frac{[\mathrm{MLH}]}{[\mathrm{M}][\mathrm{L}][\mathrm{H}]}$ & $30.01 \pm 0.05$ & $30.56 \pm 0.04$ & $26.52 \pm 0.03$ & $26.69 \pm 0.02$ \\
\hline$\frac{\left[\mathrm{MLH}_{3}\right]}{[\mathrm{M}][\mathrm{L}][\mathrm{H}]^{3}}$ & $39.56 \pm 0.04$ & $39.88 \pm 0.03$ & $36.75 \pm 0.04$ & $36.91 \pm 0.05$ \\
\hline$\frac{\left[\mathrm{MLH}_{4}\right]}{[\mathrm{M}][\mathrm{L}][\mathrm{H}]^{4}}$ & $43.56 \pm 0.06$ & $43.75 \pm 0.06$ & $40.79 \pm 0.06$ & $40.98 \pm 0.04$ \\
\hline$\frac{\left[\mathrm{HILN}_{5}\right]}{[\mathrm{M}][\mathrm{L}][\mathrm{H}]^{5}}$ & $45.43 \pm 0.06$ & $45.75 \pm 0.05$ & $44.10 \pm 0.03$ & $44.45 \pm 0.02$ \\
\hline
\end{tabular}

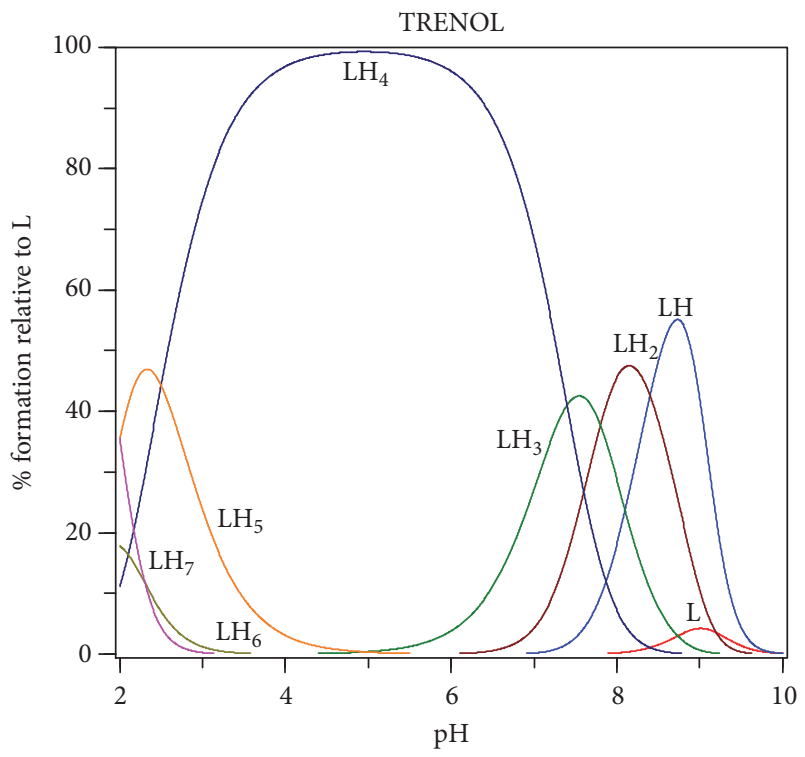

Figure 3: pH dependent species distribution curve of the ligand (TRENOL).

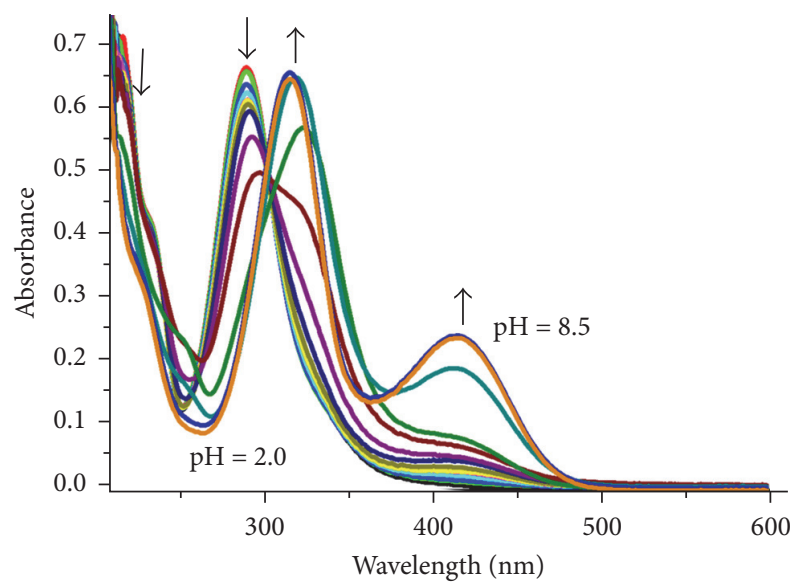

FIGURE 4: Electronic spectra of ligand as a function of $\mathrm{pH}(2.0-9.0)$ during spectrophotometric titration; $[\mathrm{L}]=2 \times 10^{-5} \mathrm{M}$ and $T=25 \pm$ $1^{\circ} \mathrm{C}$. shifting of bands from 289 to $323 \mathrm{~nm}$ corresponding to deprotonation of the aromatic ortho-OH groups. The shifting of bands towards longer wavelength is justified by the fact that on deprotonation the stabilization of $\pi^{*}$ state by charge delocalization occurs which reduces the energy of transition and also influences the absorption intensity at $423 \mathrm{~nm}$ due to the presence of conjugation between azomethine group and aromatic ring.

3.3. Metal Complexation Studies. The complexation behaviour of the ligand with $\mathrm{Fe}(\mathrm{III})$ was investigated in a $\mathrm{pH}$ range 2-9 using equimolar solution of ligand and metal ions and also with another trivalent metal ion $\mathrm{Cr}$ (III) for comparative studies. The metal-ligand potentiometric titration curves show the deviation from the ligand only at the lower $\mathrm{pH}$ region which implicates complexation of the ligand with the metal ions (Figure 2). Several models were considered to get the best fit through the refinement process. The complete agreement of the experimental and theoretical curves was obtained by considering the model as given in Table 2 .

In Fe(III)-L metal complex, no major shift in the absorption bands was obtained in the $\mathrm{pH}$ range from 2.0 to 4.0, which supported the deprotonation of nonchromophoric groups of the ligand (i.e., azomethine groups). On increasing the $\mathrm{pH}$ beyond the aforesaid range, one of the absorption bands $\left(\pi \rightarrow \pi^{*}\right)$ for aromatic ring at $289 \mathrm{~nm}$ experienced red shift $(317 \mathrm{~nm})$ with concomitant rise in absorption intensity implicating the deprotonation of $-\mathrm{OH}$ groups on aromatic ring while appearance of a low intensity band at $423 \mathrm{~nm}$ in comparison to the ligand shows the complexation of the ligand with the metal ions. Similarity in spectral changes with $\mathrm{Cr}$ (III) indicates similar mode of complexation of the chelator. Electronic spectra of the ligand with $\mathrm{Fe}(\mathrm{III})$ and $\mathrm{Cr}$ (III) were recorded between 200 and $600 \mathrm{~nm}$ as shown in Figure 5.

Analysis of the species distribution diagram of metalligand complexes as a function of $\mathrm{pH}$ showed that $\mathrm{Fe}(\mathrm{III})$ and $\mathrm{Cr}(\mathrm{III})$ coordinated to the ligand at low $\mathrm{pH}(\sim 2.0)$ through imine group with the formation of $\mathrm{MLH}_{5}$ type species (Figure 6). Coordination of weakly basic imine groups with metal ions at low $\mathrm{pH}$ is well supported by literature [11]. In the $\mathrm{pH}$ range 2-4 the deprotonated species, $\mathrm{MLH}_{4}$, was $88 \%$ for $\mathrm{Fe}(\mathrm{III})$ and $50 \%$ for $\mathrm{Cr}(\mathrm{III})$. With subsequent increase in the $\mathrm{pH}$ (4 to 8 ) the iron complexes $\mathrm{MLH}_{3}(60 \%)$, 


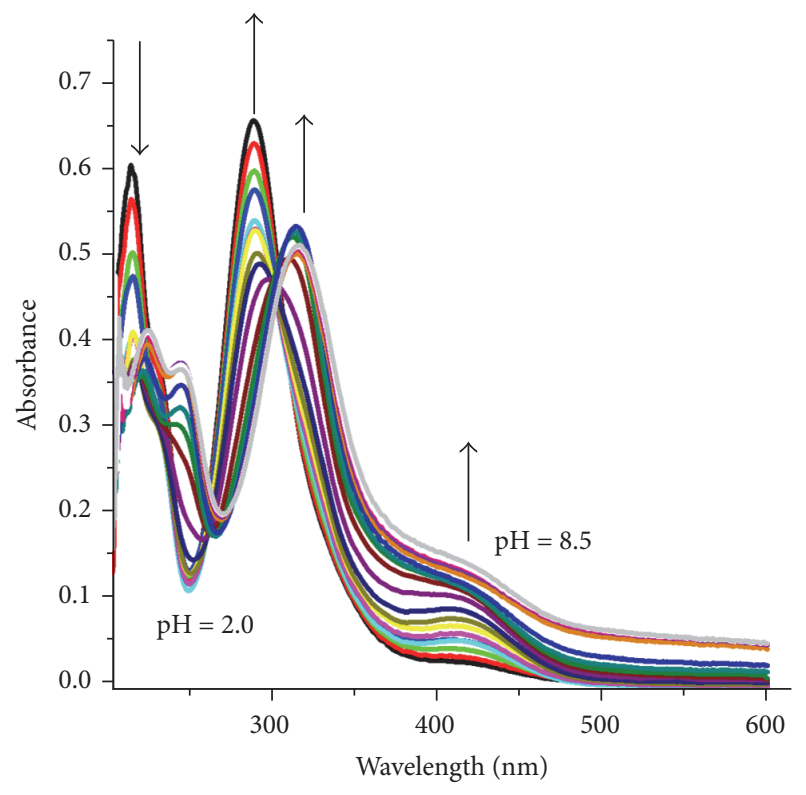

(a)

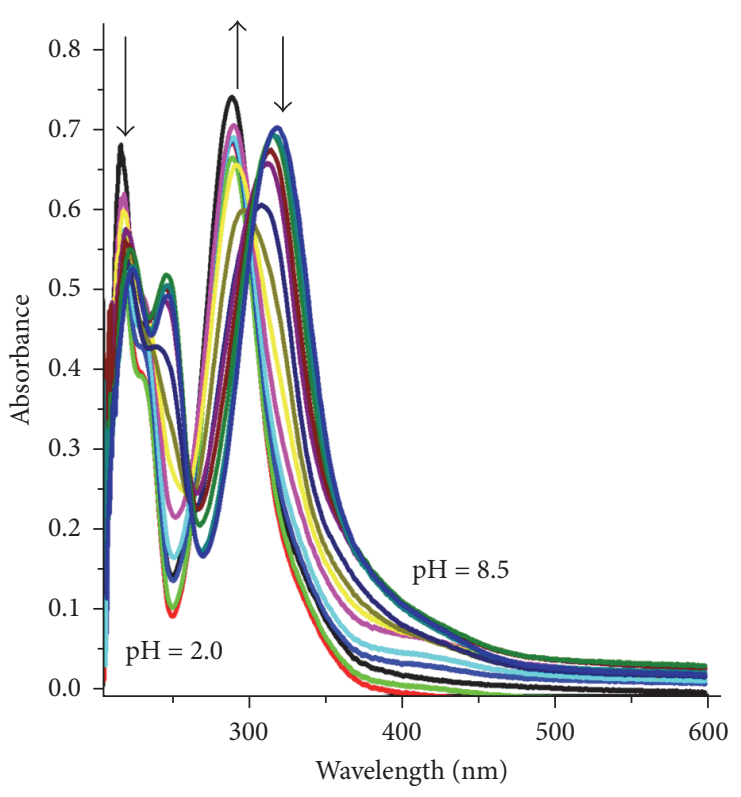

(b)

FIGURE 5: Electronic spectra of $\mathrm{L}$ as a function of $\mathrm{pH}$ during spectrophotometric titration with $[\mathrm{M}]=2 \times 10^{-5} \mathrm{M}$ where $\mathrm{M}=(\mathrm{a}) \mathrm{Fe}(\mathrm{III})$ and (b) $\mathrm{Cr}(\mathrm{III})$; [L] $=2 \times 10^{-5} \mathrm{M}$ at $\mu=0.1 \mathrm{M} \mathrm{KCl}$ and $T=25 \pm 1^{\circ} \mathrm{C}$.

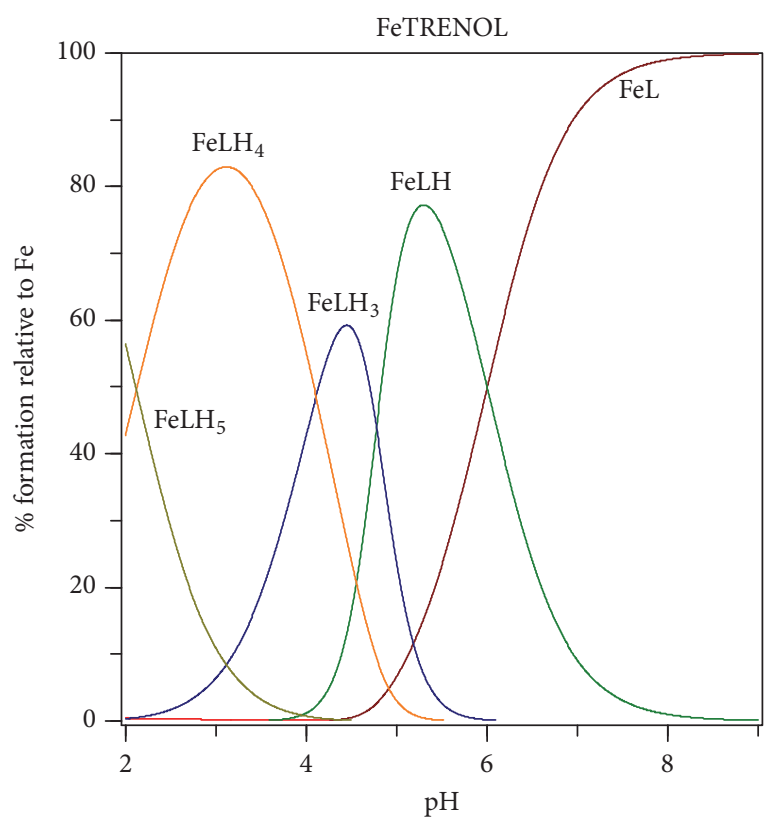

(a)

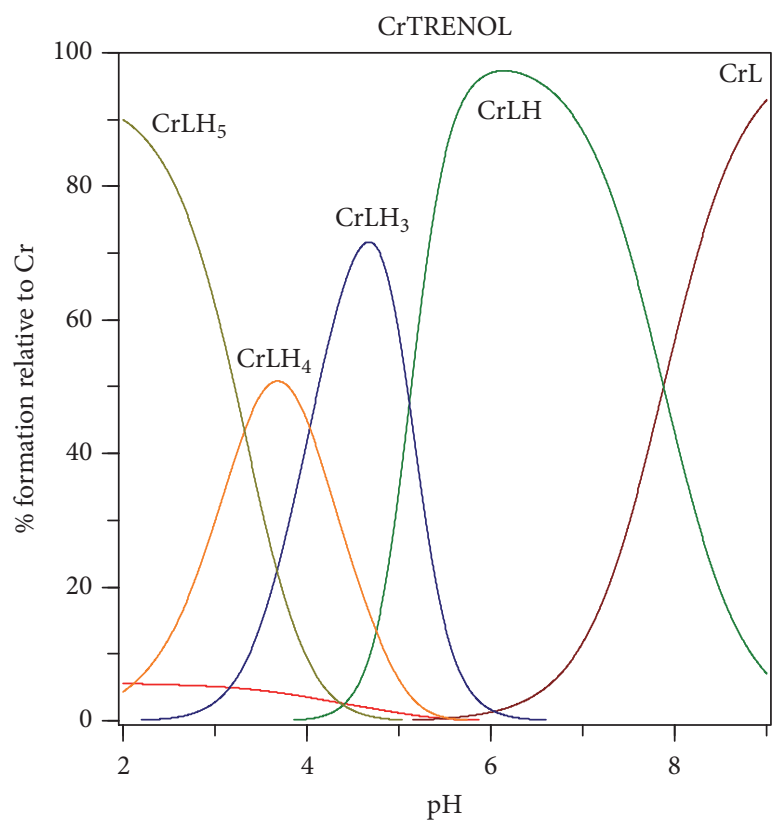

(b)

FIgURE 6: pH dependent distribution curves of the species of metal-ligand complexes (a) Fe(III)-L and (b) Cr(III)-L.

MLH (78\%), and ML (100\%) were found in the solution due to the deprotonation of aromatic hydroxy groups of the ligand. Similarly, in pH range 4-8, Cr(III) formed $\mathrm{MLH}_{3}$ (80\%), MLH (91\%), and ML (92\%) species in the solution. The deprotonation of the ligand in the presence of metal ions at lower $\mathrm{pH}$ range ( 4 to 6 for $\mathrm{Fe}$ (III) and 4.2 to 7.2 for $\mathrm{Cr}$ (III)) in comparison to the ligand alone ( $\mathrm{pH} 6$ to 8 ) was justified by the higher preference of the metal ions for the donor atoms of the ligand ( $\mathrm{O}$ and $\mathrm{N}$ ) when compared to protons. However, the potentiometric data of the ligand showed that, in $\mathrm{pH}$ range 4-6, deprotonation of the apical nitrogen occurred which might be overlapped by the deprotonation of chromophoric group in the presence of metal ions. The prediction was also well supported through the analysis of electronic absorption spectra of the metal complexes in the same region. Such deviation in the deprotonation behaviour 


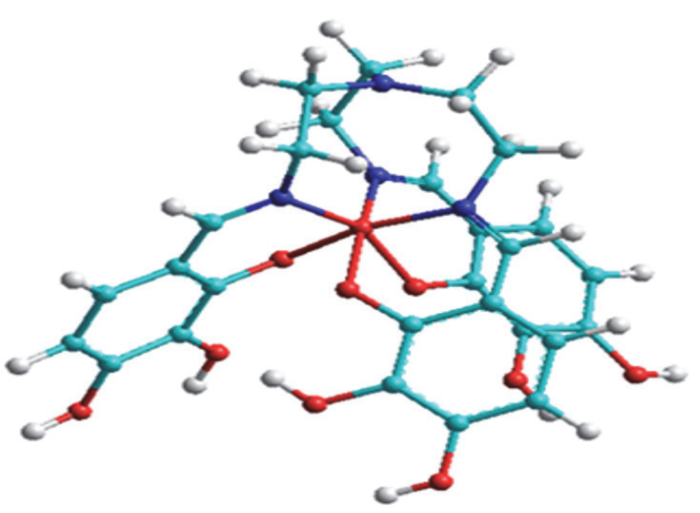

(a)

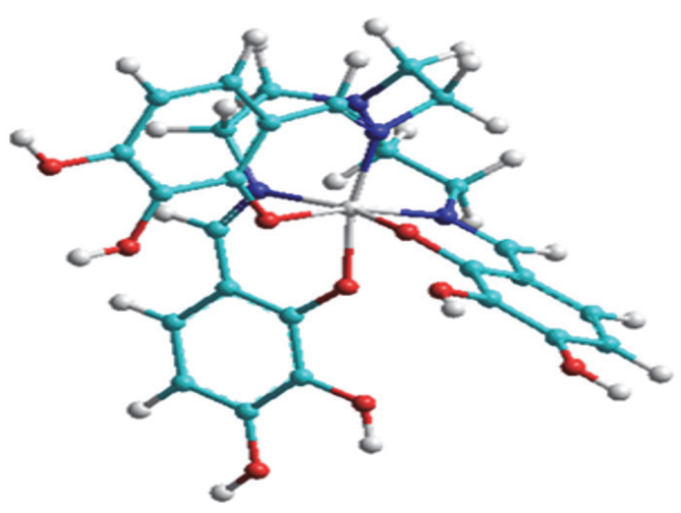

(b)

FIgURE 7: Lowest energy structures of M-L complexes (a) Fe(III)-L and (b) Cr(III)-L.

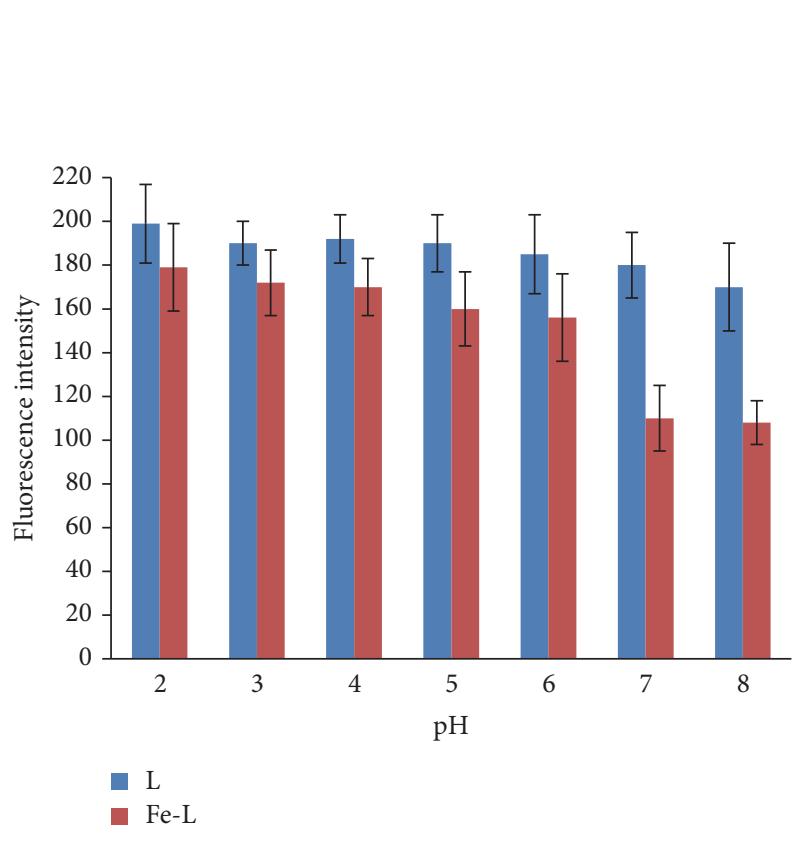

(a)

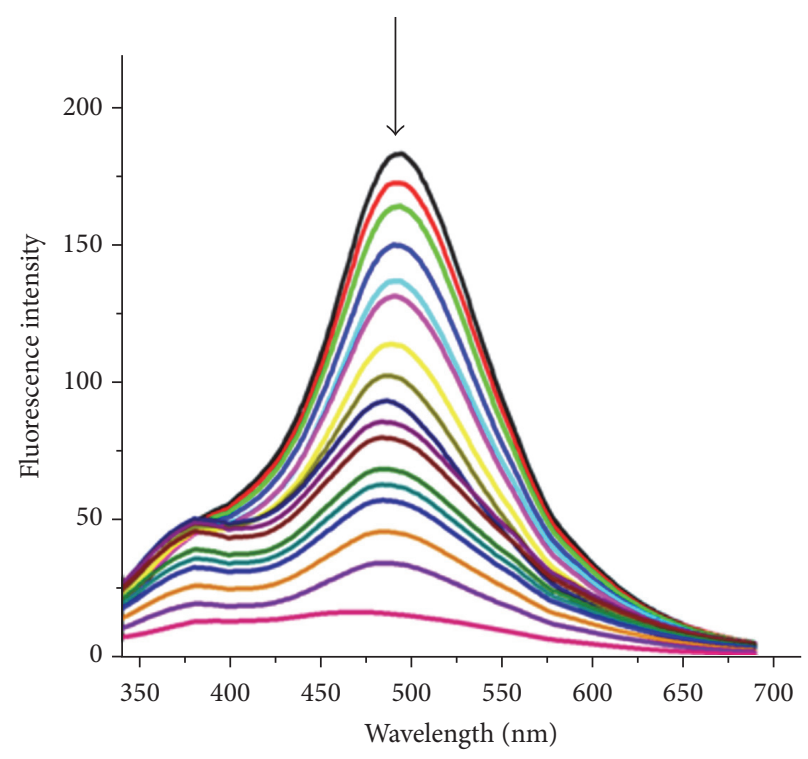

(b)

FIGURE 8: (a) pH dependent fluorescence intensities with standard deviations of ligand (L) and Fe(III)-L. (b) Fluorescence spectra of the ligand with increasing concentration of $\mathrm{Fe}(\mathrm{III})$, where $[\mathrm{L}]=20 \mu \mathrm{M}$ and $[\mathrm{Fe}(\mathrm{III})]=2$ to $1000 \mu \mathrm{M}$ (from top to bottom) at $\mathrm{pH}=7.4, \lambda_{\mathrm{ex}}=$ $289 \mathrm{~nm}$, and $\lambda_{\mathrm{em}}=496 \mathrm{~nm}$.

of the apical nitrogen has also been discussed in the literature with several different concepts according to their ligand structures [45].

In order to depict the coordination mode of the ligand with metal ions, molecular modeling studies were carried out for all the formed species of metal-ligand complexes $\left(\mathrm{MLH}_{5}, \mathrm{MLH}_{4}, \mathrm{MLH}_{3}, \mathrm{MLH}\right.$, and ML) using molecular mechanics with MM+ force field [39] followed by optimization by semiempirical PM3 parameters [40]. Among these species, M-L type species was found to be the most stable species based on the least strain minimum energy structures (Figure 7). Moreover, bond length and bond angles for the ML type complexes were calculated and it was found that the metal complexes possessed distorted octahedral geometry.
3.4. Studies of Photophysical Properties. The fluorescence behaviour of the ligand was investigated in the wavelength range $350-700 \mathrm{~nm}$ under similar conditions as done in spectrophotometric method. The ligand exhibited fluorescence at $496 \mathrm{~nm}$ with slit width $20 \mathrm{~nm}$ and $\lambda_{\text {ex }}=289 \mathrm{~nm}$. Presence of transition metal ions in the vicinity of fluorophore changes its photophysical properties through modulated oxidation potential of the donor group leading to fluorescence enhancement or quenching $[46,47]$. The fluorescence behaviour of the ligand was initially studied in the presence of $\mathrm{Fe}(\mathrm{III})$ with variation in $\mathrm{pH}$, given in Figure 8(a). TRENOL exhibited maximum quenching between $\mathrm{pH} 7$ and $\mathrm{pH} 8$ after which precipitation occurred. The fluorescence behaviour of the ligand was also studied at different concentrations of $\mathrm{Fe}(\mathrm{III})$ 


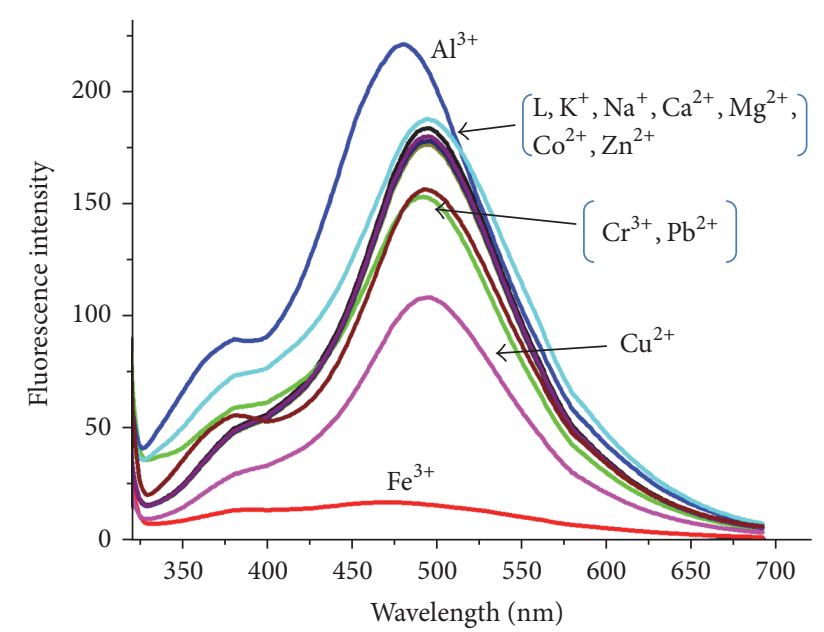

FIGURE 9: Fluorescence spectra of TRENOL in presence of different metal ions: $[\mathrm{L}]=20 \mu \mathrm{M},[\mathrm{M}]=1000 \mu \mathrm{M}$ at $\lambda_{\mathrm{ex}}=289 \mathrm{~nm}$, and $\mathrm{pH}=$ 7.4 .

at physiological $\mathrm{pH}$ (Figure $8(\mathrm{~b})$ ). The detection limit of the $\mathrm{Fe}(\mathrm{III})$ was found to be around $1.4 \times 10^{-5} \mathrm{M}$.

To explore more on the ligand's selectivity in fluorescence sensing, different metal ions such as $\mathrm{Na}^{+}, \mathrm{K}^{+}, \mathrm{Ca}^{2+}, \mathrm{Mg}^{2+}$, $\mathrm{Zn}^{2+}, \mathrm{Co}^{2+}, \mathrm{Pb}^{2+}, \mathrm{Cu}^{2+}, \mathrm{Al}^{3+}$, and $\mathrm{Cr}^{3+}$ were taken for the study. Figure 9 shows fluorescence quenching in the ligand with $\mathrm{Fe}(\mathrm{III})$ as compared to other metal ions used. The quenching is maximum (9-fold compared to ligand alone) with $[\mathrm{Fe}(\mathrm{III})]=1000 \mu \mathrm{M}$ at physiological $\mathrm{pH}$, whereas none of the above-mentioned metals showed any significant effect. However, the ligand shows little quenching ( 1.5-fold) in presence of $\mathrm{Cu}(\mathrm{II})$ and negligible quenching $(\sim 0.5$-fold $)$ with $\mathrm{Pb}(\mathrm{II})$ and $\mathrm{Cr}(\mathrm{III})$.

\section{Conclusions}

In summary a novel tris(2-aminoethyl)amine based tripodal ligand, TRENOL with seven protonation constants in $\mathrm{pH}$ range 2-11, was developed that served as a potential $\mathrm{Fe}$ (III) binding chelator. The preorganized structure of the ligand offered a favorable environment for a strong encapsulation of $\mathrm{Fe}(\mathrm{III})$ with high binding constant value (ML, $\log \beta=$ 24.01 ) as compared to $\mathrm{Cr}(\mathrm{III})$. Moreover, the tripodal chelator showed fluorescence through assisted ESIPT mechanism at $490 \mathrm{~nm}$. The fluorescence behaviour of the ligand exhibited maximum quenching in the presence of Fe(III) metal ions at physiological $\mathrm{pH}$ in comparison to other biological relevant metal ions and limit of detection for the $\mathrm{Fe}(\mathrm{III})$ was found to be $1.4 \times 10^{-5} \mathrm{M}$. Therefore, the ligand (L) may be cited as an alternate for the detection of iron for further modification to develop a better potent fluorescence sensor.

\section{Competing Interests}

The authors declare that they have no competing interests.

\section{Acknowledgments}

The authors would like to thank the Department of Chemistry, National Institute of Technology, Kurukshetra, for providing the facilities.

\section{References}

[1] S. Touriño, D. Lizárraga, A. Carreras et al., "Antioxidant/prooxidant effects of bioactive polyphenolics," Electronic Journal of Environmental, Agricultural and Food Chemistry, vol. 7, no. 8, pp. 3348-3352, 2008.

[2] A. M. Abu-Dief and I. M. A. Mohamed, "A review on versatile applications of transition metal complexes incorporating Schiff bases," Beni-Suef University Journal of Basic and Applied Sciences, vol. 4, no. 2, pp. 119-133, 2015.

[3] M. A. Ashraf, K. Mahmood, and A. Wajid, "Synthesis, characterization and biological activity of Schiff bases," in Proceedings of the International Conference on Chemistry and Chemical Process (ICCCP '11), vol. 53, pp. 1-7, Bangkok, Thailand, 2011.

[4] S. L. Byrne, D. Krishnamurthy, and M. Wessling-Resnick, "Pharmacology of iron transport," Annual Review of Pharmacology and Toxicology, vol. 53, pp. 17-36, 2013.

[5] G. Winkle Mann and C. J. Carrano, Transition Metals in Microbial Metabolism, Harwood Academic, Amsterdam, The Netherlands, 1997.

[6] G. Winkle Mann, Handbook of Microbial Iron Chelates, CRC Press, New York, NY, USA, 1998.

[7] C. R. Lloyd, F. C. Cleary, H.-Y. Kim et al., "Is what you eat and drink safe? Detection and identification of microbial contamination in foods and water," Proceedings of the IEEE, vol. 91, no. 6, pp. 908-914, 2003.

[8] H. Y. Mason, C. Llyod, M. Dice, R. Cinclair, and W. Ellis Jr., "Taxonomic identification of microorganisms by capture and intrinsic fluorescence detection," Biosensors and Bioelectronics, vol. 18, no. 5-6, pp. 521-527, 2003.

[9] S. G. John, C. E. Ruggiero, L. E. Hersman, C.-S. Tung, and M. P. Neu, "Siderophore mediated plutonium accumulation by Microbacterium flavescens (JG-9)," Environmental Science and Technology, vol. 35, no. 14, pp. 2942-2948, 2001.

[10] C. E. Ruggiero, J. H. Matonic, S. D. Reilly, and M. P. Neu, "Dissolution of plutonium(IV) hydroxide by desferrioxamine siderophores and simple organic chelators," Inorganic Chemistry, vol. 41, no. 14, pp. 3593-3595, 2002.

[11] T. Yoshida, T. Ozaki, T. Ohnuki, and A. J. Francis, "Adsorption of Th (IV) and Pu (IV) on the surface of pseudomonas fluorescens and bacillus subtilis in the presence of desferrioxamine siderophore," Journal of Nuclear and Radiochemical Sciences, vol. 6, no. 1, pp. 77-80, 2005.

[12] S. J. Rodgers, C. W. Lee, C. Y. Ng, and K. N. Raymond, "Ferric ion sequestering agents. 15 . Synthesis, solution chemistry, and electrochemistry of a new cationic analog of enterobactin," Inorganic Chemistry, vol. 26, no. 10, pp. 1622-1625, 1987.

[13] M. J. Miller, "Syntheses and therapeutic potential of hydroxamic acid based siderophores and analogues," Chemical Reviews, vol. 89, no. 7, pp. 1563-1579, 1989.

[14] R. J. Bergeron, J. Wiegand, J. S. Mcmanis, and P. T. Perumal, "Synthesis and biological evaluation of hydroxamate-based iron chelators," Journal of Medicinal Chemistry, vol. 34, no. 11, pp. 3182-3187, 1991. 
[15] A. L. Crumbliss, "Iron bioavailability and the coordination chemistry of hydroxamic acids," Coordination Chemistry Reviews, vol. 105, pp. 155-179, 1990.

[16] J. H. Crosa, "Genetics and molecular biology of siderophoremediated iron transport in bacteria," Microbiology and Molecular Biology Reviews, vol. 53, no. 4, pp. 517-530, 1989.

[17] J. B. Porter, "A risk-benefit assessment of iron-chelation therapy," Drug Safety, vol. 17, no. 6, pp. 407-421, 1997.

[18] M. Y. Moridani, G. S. Tilbrook, H. H. Khodr, and R. C. Hider, "Synthesis and physicochemical assessment of novel 2-substituted 3-hydroxypyridin-4-ones, novel iron chelators," Journal of Pharmacy and Pharmacology, vol. 54, no. 3, pp. 349364, 2002.

[19] M. A. Santos, S. M. Marques, and S. Chaves, "Hydroxypyridinones as 'privileged' chelating structures for the design of medicinal drugs," Coordination Chemistry Reviews, vol. 256, no. 1-2, pp. 240-259, 2012.

[20] M. M. Meijler, R. Arad-Yellin, Z. I. Cabantchik, and A. Shanzer, "Synthesis and evaluation of iron chelators with masked hydrophilic moieties," Journal of the American Chemical Society, vol. 124, no. 43, pp. 12666-12667, 2002.

[21] F. L. Weitl and K. N. Raymond, "Ferric ion sequestering agents. 1. Hexadentate O-bonding N,N'N"-tris(2,3-dihydroxybenzoyl) derivatives of 1,5,9-triazacyclotridecane and 1,3,5-triaminomethylbenzene," Journal of the American Chemical Society, vol. 101, no. 10, pp. 2728-2731, 1979.

[22] F. L. Weitl and K. N. Raymond, "Specific sequestering agents for the actinides. 3. Polycatecholate ligands derived from 2,3dihydroxy-5-sulfobenzoyl conjugates of diaza- and tetraazaalkanes," Journal of the American Chemical Society, vol. 102, no. 7, pp. 2289-2293, 1980.

[23] K. N. Raymond, G. Muller, and B. F. Matzanke, Topics in Current Chemistry, Springer, Berlin, Germany, 1984.

[24] G. Crisponi and M. Remelli, "Iron chelating agents for the treatment of iron overload," Coordination Chemistry Reviews, vol. 252, no. 10-11, pp. 1225-1240, 2008.

[25] K. N. Raymond, G. Mueller, and B. F. Matzanke, "Complexation of iron by siderophores: a review of their solution and structural chemistry and biological function," in Topics in Current Chemistry, F. L. Boschke, Ed., vol. 123, pp. 49-102, Springer, Berlin, Germany, 1984.

[26] M. Hayashi, K. Hirtani, M. Ishii, K. Saigo, and S. H. Kina, "Synthesis of cyclopentane-containing marine eicosanoid bacillariolide II," Tetrahedron Letters, vol. 39, no. 7, pp. 621-624, 1998.

[27] N. Cheraiti, M. E. Brik, G. Kunesch, and A. Gaudemer, "Synthesis of the smallest tris-(catecholamide) siderophore analogue," Journal of Organometallic Chemistry, vol. 575, no. 1, pp. 149-152, 1999.

[28] V. L. Pecoraro, F. L. Weit, and K. N. Raymond, "Ferric ionspecific sequestering agents. 7. Synthesis, iron-exchange kinetics, and stability constants of N-substituted, sulfonated catechoylamide analogs of enterobactin," Journal of the American Chemical Society, vol. 103, no. 17, pp. 5133-5140, 1981.

[29] J. C. Ryu, H. N. Shin, D. N. Kim, and S. H. Lee, "Enterobactin analogues prepared by cross-linking catechol derivative with cis,cis-1,3,5-Tris(aminomethyl)cyclohexane," Bulletin of the Korean Chemical Society, vol. 22, no. 12, pp. 1293-1294, 2001.

[30] B. K. Kanungo, M. Baral, S. K. Sahoo, and S. E. Muthu, "Synthesis, spectroscopic and theoretical studies of two novel tripodal imine-phenol ligands and their complexation with
Fe(III)," Spectrochimica Acta-Part A: Molecular and Biomolecular Spectroscopy, vol. 74, no. 2, pp. 544-552, 2009.

[31] S. K. Sahoo, M. Baral, and B. K. Kanungo, "Tripodal amine catechol ligands: a fascinating class of chelators for aluminium(III)," Journal of Inorganic Biochemistry, vol. 102, no. 8, pp. 1581-1588, 2008.

[32] S. K. Sahoo, M. Baral, and B. K. Kanungo, "Potentiometric, spectrophotometric, theoretical studies and binding properties of a novel tripodal polycatechol-amine ligand with lanthanide(III) ions," Polyhedron, vol. 25, no. 3, pp. 722-736, 2006.

[33] R. K. Bera, M. Baral, S. K. Sahoo, and B. K. Kanungo, "Spectroscopic, potentiometric and theoretical studies of novel iminophenolate chelators for Fe(III)," Spectrochimica Acta-Part A: Molecular and Biomolecular Spectroscopy, vol. 134, pp. 165-172, 2015.

[34] D. A. Safin and Y. Garcia, "First evidence of thermo- and twostep photochromism of tris-anils," RSC Advances, vol. 3, no. 18, pp. 6466-6471, 2013.

[35] B. S. Furniss, A. J. Hannaford, P. W. G. Simth, and A. R. Tatchell, Vogel's Text Book of Practical Organic Chemistry, Prentice Hall, 5th edition, 2008.

[36] P. Gans, A. Sabatini, and A. Vacca, "Investigation of equilibria in solution. Determination of equilibrium constants with the HYPERQUAD suite of programs," Talanta, vol. 43, no. 10, pp. 1739-1753, 1996.

[37] L. Alderighia, P. Gans, A. Ienco, D. Peters, A. Sabatini, and A. Vacca, "Hyperquad simulation and speciation (HySS): a utility program for the investigation of equilibria involving soluble and partially soluble species," Coordination Chemistry Reviews, vol. 184, no. 1, pp. 311-318, 1999.

[38] P. Gans, A. Sabatini, and A. Vacca, "Determination of equilibrium constants from spectrophotometric data obtained from solution of known pH: the program pHab," Annali di Chimica, vol. 89, pp. 45-49, 1999.

[39] S. Lee, B. A. Rao, and Y.-A. Son, "A highly selective fluorescent chemosensor for $\mathrm{Hg}^{2+}$ based on a squaraine-bis(rhodamine- $\mathrm{B}$ ) derivative: part II," Sensors and Actuators B: Chemical, vol. 210, pp. 519-532, 2015.

[40] HyperChem Version 7.5, Hypercube Inc, Waterloo, Canada, 2003.

[41] P. J. J. Stewart, MOPAC2012, Version 12.239W, Stewart Computational Chemistry, Colorado Springs, Colo, USA, 2012.

[42] S. Chaves, A. C. Mendonça, S. M. Marques et al., "A gallium complex with a new tripodal tris-hydroxypyridinone for potential nuclear diagnostic imaging: solution and in vivo studies of ${ }^{67}$ Ga-labeled species," Journal of Inorganic Biochemistry, vol. 105, no. 1, pp. 31-38, 2011.

[43] A. Golcu, M. Tumer, H. Demirelli, and R. A. Wheatley, "Cd(II) and $\mathrm{Cu}$ (II) complexes of polydentate Schiff base ligands: synthesis, characterization, properties and biological activity," Inorganica Chimica Acta, vol. 358, no. 6, pp. 1785-1797, 2005.

[44] S. K. Sahoo, S. E. Muthu, M. Baral, and B. K. Kanungo, "Potentiometric and spectrophotometric study of a new dipodal ligand N,N /-bis2-[(2-hydroxybenzylidine)amino] ethylmalonamide with $\mathrm{Co}(\mathrm{II}), \mathrm{Ni}(\mathrm{II}), \mathrm{Cu}(\mathrm{II})$ and $\mathrm{Zn}(\mathrm{II})$," Spectrochimica Acta-Part A: Molecular and Biomolecular Spectroscopy, vol. 63, no. 3, pp. 574-586, 2006.

[45] A. C. Mendonça, A. F. Martins, A. Melchior et al., "New tris-3,4HOPO lanthanide complexes as potential imaging probes: complex stability and magnetic properties," Dalton Transactions, vol. 42, no. 17, pp. 6046-6057, 2013. 
[46] N. Singh, N. Kaur, and J. F. Callan, "Incorporation of siderophore binding sites in a dipodal fluorescent sensor for Fe(III)," Journal of Fluorescence, vol. 19, no. 4, pp. 649-654, 2009.

[47] J. Li, N. Zhang, F. Dai, Q. Luo, and Y. Ji, "Metrological array of cyber-physical systems. Part 1. Challenge of modernity," Sensors and Transducers, vol. 186, pp. 125-128, 2015. 

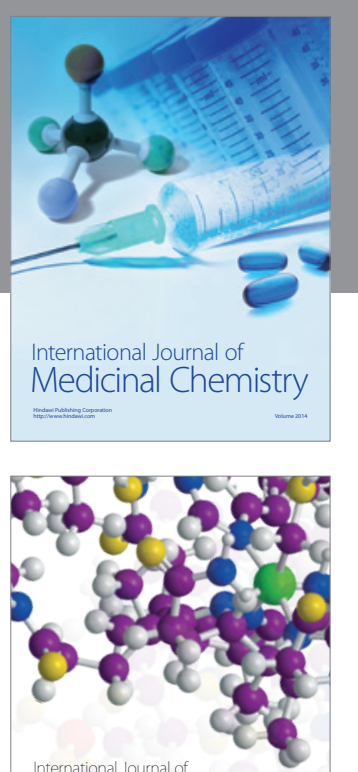

Carbohydrate Chemistry

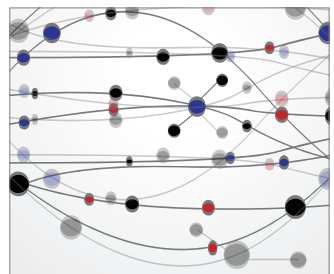

The Scientific World Journal
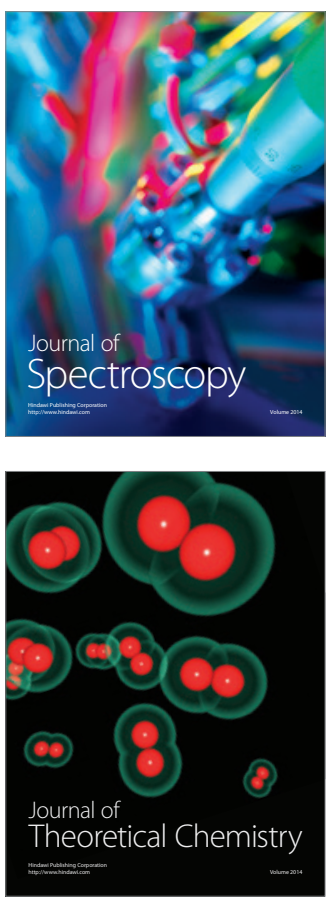
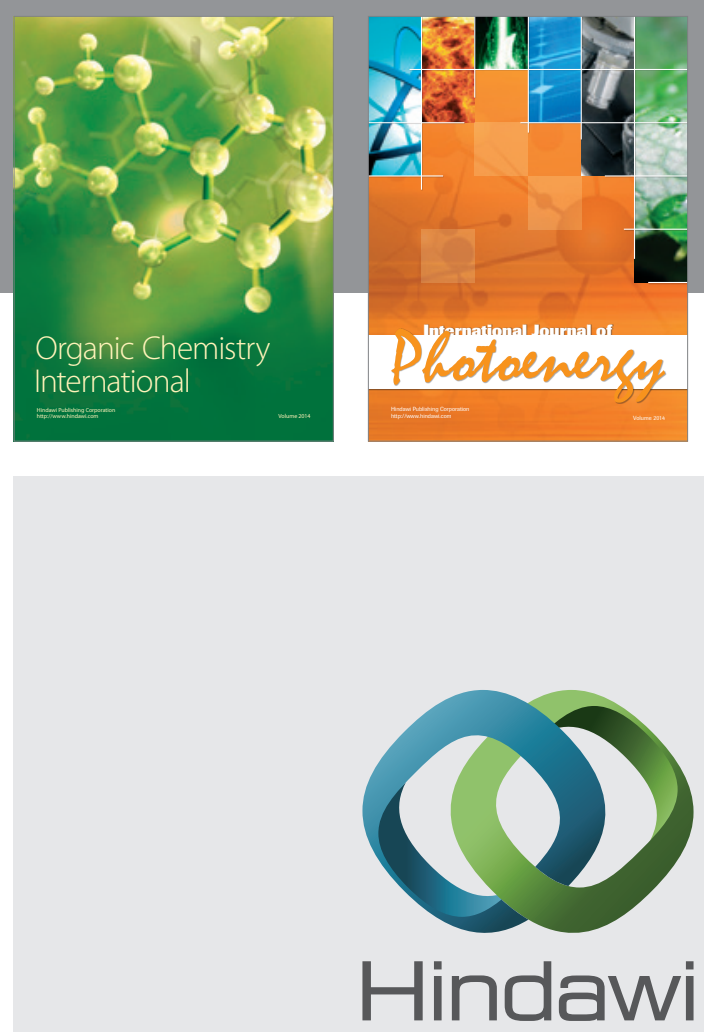

Submit your manuscripts at

http://www.hindawi.com

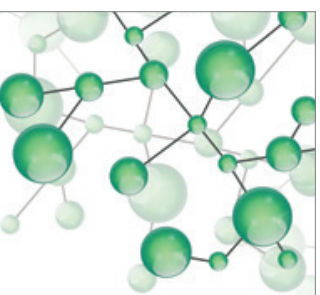

International Journal of

Inorganic Chemistry

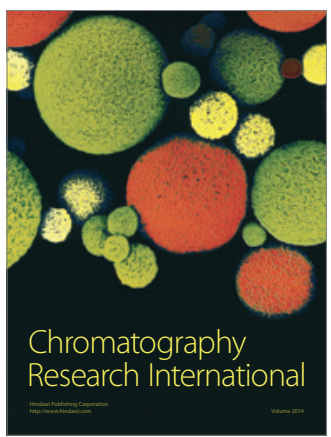

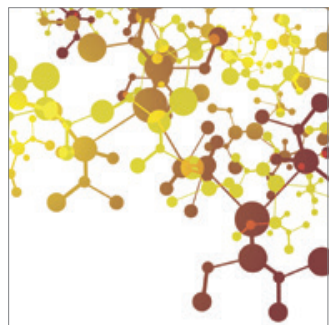

Applied Chemistry
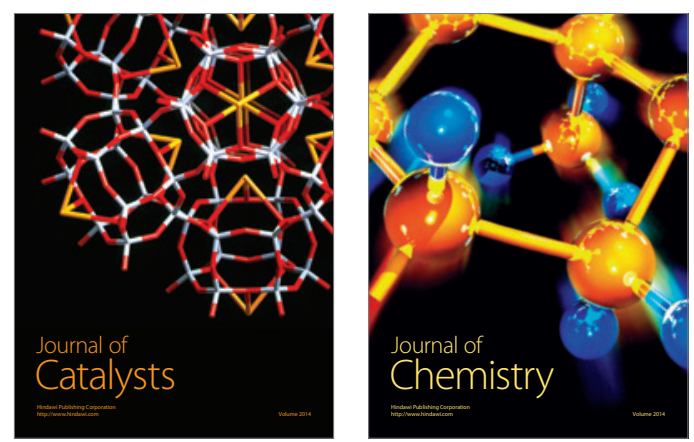
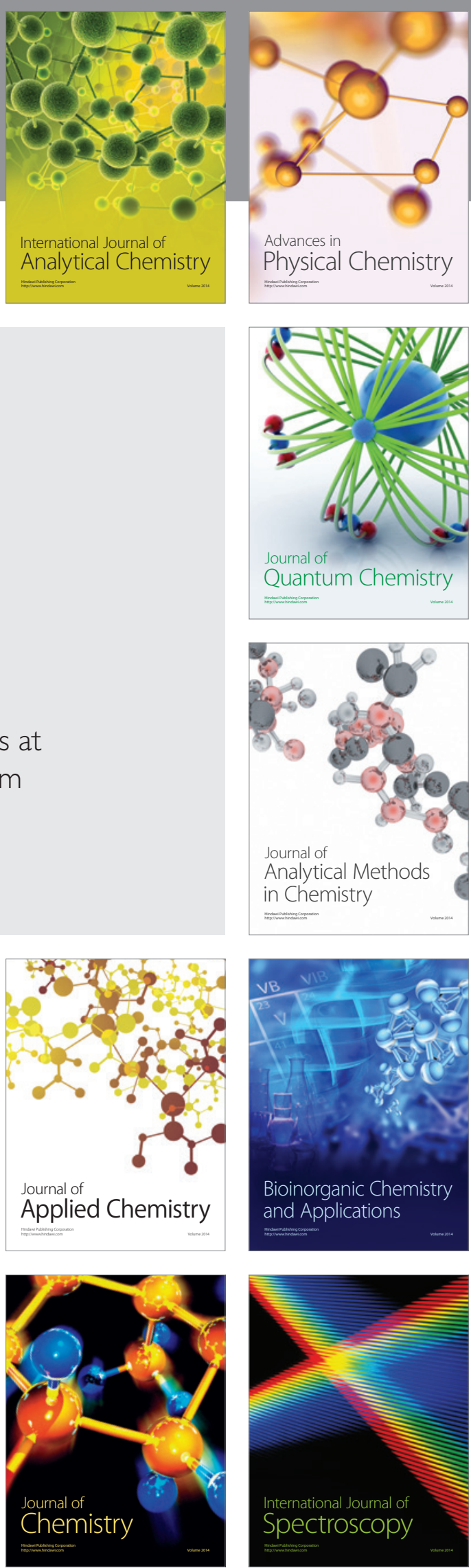